\title{
Causes and Treatment of Feline Dystocia
}

\author{
Uday, T. Naoman* \\ Department of Surgery and Theriogenology, College of Veterinary Medicine, University of Mosul, Iraq. \\ *Corresponding Author, Uday T. Naoman, E-Mail: uday.naoman@uomosul.edu.iq
}

\begin{abstract}
The objective of the present study was to describe retrospective data, including causes and whether medical and surgical management is suitable for feline dystocia. Data were analysed and described according to original causes and treatment protocols were done. Data of this study revealed that the maternal causes with different types of dystocia were the major percentage. The highest percentage was recorded in 2020 which was $80.00 \%$, while the lowest rate was in 2018 which was $66.00 \%$. The highest foetal causes percentages were in 2018 which was $33.00 \%$, while the lowest rate was in 2020 which was $20.00 \%$. Data also revealed the percentage of treatment types for dystocia in cats in the period between 2018-2021 which were $17.07 \%$ of hormonal treatment and $82.93 \%$ of Caseran Section operation. Results of the present study conclude that the best method for treating dystocia in cats was the cesarean section. The author advised using estrogen and Oxytocin hormones with $\mathrm{Ca}^{++}$to treat the non-obestracting dystocia or hormonal treatment instead of using oxytocin and $\mathrm{Ca}^{++}$alone.
\end{abstract}

Keywords: Cat, Cesarean Section, Dystocia, Hormonal treatment.
Original Article:

DOI:https://dx.doi.org/10.21608/javs .2021.87891.1093

Received :27 July, 2021.

Accepted :25 August, 2021.

Published in October, 2021.

This is an open access article under the term the Creative Commons Attribution 4.0 (CC-B International License . To view a copy of tl license, visit:

http://creativecommons.org/licenses/by/4.0/

\section{INTRODUCTION}

Dystocia in cat (queen) is defined as difficulty in the exploding of the fetus or delivery of the kitten through the birth canal at the time (6-12 hours) of labor (Dar et al., 2015). The causes of dystocia are classified into those caused by maternal, those caused by fetal, and in some cases combination between them (GunnMoor and Thrusfield, 1995; Stedile et al., 2011). Not enough research has been published on the incidences of dystocia in cats (Felis catus) has been conducted.

The major cause related to the dam representing by two types of uterine inertia; the first one is called "primary" which mean that condition in which the uterine muscles do not contract, the other type of uterine inertia is "secondary" which mean fatigued during labor from tenacious straining beside an obstruction within the birth canal (Talukder et al., 2021; Li et al., 2021), The other dam-related cause partial or incomplete dilation of the cervix (Jakson, 2004).

A narrowing of the birth canal can also be undergone as a maternal cause of dystocia and healthy status. The fetal origin of dystocia may be related to the fetus's head, which may be too large to pass through the birth canal, or the fetus may be oversized or malformed. Sometimes an abnormal presentation, position, and posture of the fetus made difficult delivery (Pretzer, 2008). Physiological stress can delay the onset of labor (Oliviera et al., 2016). A rare cause of dystocia is twisting the uterus on itself (uterine torsion) (Ekstrand and Forsberg, 1994). The incidence of dystocia in cats is around 3.3-5.8 in some breeds of cats (Pretzer, 2008). Overall, 67.1 percent of instances have been linked to maternal factors, while 29.7\% have been linked to fetal factors (Jyothi and Rajesh, 2018).

Treatment of dystocia is divided into medical and surgical treatments with different aspects depended upon causes, physical examination, diagnosis of the problems, and types of uterine inertia (Trass 2008). Medical treatment including oxytocin and calcium alone with physical manipulation of the vagina to assisted delivery (Pretzer, 2008). The cesarean section must be performed as soon as feasible as another way for treatment dystocia in case of destructive dystocia or when medical treatment fails or is not practicable (Olivira, 2016). The objective of this study was to describe retrospective data including causes and whether medical and surgical management is suitable for feline dystocia. 


\section{MATERIIALS AND METHODS}

Data of this study includes a total of 41 clinical cases brought by the owners to the Teaching Hospital related to the College of Veterinary Medicine, University of Mosul and some Clinic centers distributed in Mosul city, Iraq during the period between 2018-2021. According to clinical examination and case history, the involved cats are classified as dystocia from different breeds.

\section{Clinical examination and physical examination:}

After the cats were brought to the clinic., a complete case history was recorded from the owner including name, age, previous labor, the time when parturition signs began and delivery of fetus or more than one occurrence or not. Animal weighing, body temperature and pulse rate with noticing animal body condition were done.

\section{Physical examination:}

The physical examination was done after weighing and tight of the animal may be necessary sometimes. Vaginal examination (if possible) and the present character of vaginal discharge were recorded and distinguish, if present or noted. Abdominal palpation to assist uterine size and number of remaining fetuses. $\beta$-mode Ultrasonography was used to check fetal viability, malformation, fetal distress, and placental integrity. Fetal heart rates of 140-160 beats/min consider poor viability and need immediate veterinary intervention. Sterile artery forceps may be used to draw the fetus if it is stuck in the birth canal.

\section{Treatment:}

Treatment protocol or type depending upon the status of cervix or presence of ring womb. Medical treatment choice is considering in case of opening or partial dilatation of the cervix, and C-sections were considered in case of the complete closed cervix or giant fetus. Also, animal body condition takes into account.

\section{Medical treatment:}

Medical treatment is based on estrogenoxytocin combination protocol in the same way described by (Purohit et al., 2011). injection of estrogens could be helpful in a completely closed cervix and injections of oxytocin are given to promote uterine contraction to affect cervical dilation when it is partially dilated. Intramuscular injection of $0.5 \mathrm{mg}$ of estrogen $0.2 \%$ (Estradiol benzoate, Hebei Chengshengtang Animal Pharmaceutical Co., Ltd, China) and after 4-6 hours later 5 IU of oxytocin $10 \%$ ( Intercheme Inc., Holland) was injected intramuscularly. Calcium gluconate $10 \%$ in dose $0.5-0.1 \mathrm{ml} / \mathrm{kg}$ for subcutaneous injection. Glucose Saline $0.9 \%$ for IV infusion was indicated if the case required shock and electrolyte imbalance.

\section{Surgical treatment:}

Cesarean section is done in the way described by (Dar et al., 2015). Atropine sulfate at the rate of $0.04 \mathrm{mg} / \mathrm{kg}$ and Xylazine at the rate of $1 \mathrm{mg} / \mathrm{kg}$ intramuscularly used as premedicated and Induction of anesthesia was done with a combination of diazepam at the dose rate of $0.27 \mathrm{mg} / \mathrm{kg}$ plus ketamine at the dose rate of $5.5 \mathrm{mg} / \mathrm{kg}$ intramuscularly. The site of operation was prepared for aseptic surgery, secured, and draped. After restraining the animal in dorsal recumbency, a ventral midline incision just caudal to the umbilicus was opened, uterus was incised at the body, and fetuses inside were removed with fetal membrane. The uterus was flushed with normal saline and closed. The operation was done in the way described by (Olivira 2016) with post-operation medication and oxytocin was given.

\section{Statical analysis:}

Data were analyzed by using the SPSS program (SPSS 2003, SPSS Inc.) to find the mean and total percentage for treatment cases.

\section{RESULTS}

The results of the present study were summarized in Table 1. Table 1 shows causes of dystocia percentage and type of dystocia origin in cats. It is revealed that maternal origin with different types of dystocia was the major percentage, and it reaches up $66 \%, 75 \%, 80 \%, 68.75 \%$ in $2018,2019,2020,2021$, respectively. The foetal causes percentages $34 \%, 25 \%$, $20 \%, 31.25 \%$ in $2018,2019,2020,2021$ respectively. Table 2 shows the percentage of treatment types for dystocia in cats in the period between 2018-2021 which were $17.07 \%$ of hormonal treatment and $82.93 \%$ of C-sections.

Table 1 shows the causes of dystocia percentage and type of dystocia origin in cats between 2018-2021.

\begin{tabular}{|l|c|c|c|c|}
\hline Causes of dystocia & 2018 & 2019 & 2020 & 2021 \\
\hline Total cases & 15 & 12 & 5 & 16 \\
\hline Maternal & & & & \\
\hline Uterine inertia & 7 & 8 & 4 & 10 \\
\hline Narrow birth canal & 1 & 1 & ---- & 1 \\
\hline Uterine torsion & 1 & --- & ----- & ---- \\
\hline Uterine prolapse & 1 & --- & ---- & ---- \\
\hline Total (maternal) & 10 & 9 & 4 & 11 \\
\hline Total percentage \% & $66 \%$ & $75 \%$ & $80 \%$ & $68.75 \%$ \\
\hline Fetal & & & & \\
\hline Fetal malposition & 3 & 2 & 1 & 2 \\
\hline Fetal oversize & 1 & 1 & ---- & 2 \\
\hline fetal malformation & ---- & --- & ---- & 1 \\
\hline Fetal death & 1 & ---- & ---- & --- \\
\hline Total (Fetal) & 5 & 3 & 1 & 5 \\
\hline Total percentage \% & $34 \%$ & $25 \%$ & $20 \%$ & $31.25 \%$ \\
\hline
\end{tabular}


Table 2: shows the percentage of types of treatment for dystocia in cats in the period between 2018-2021.

\begin{tabular}{|l|c|c|}
\hline Type of treatment & Numbers & $\begin{array}{c}\text { Total } \\
\text { percentage } \\
100 \%\end{array}$ \\
\hline Hormonal treatment & $(7 / 41)$ & 17.07 \\
\hline Cesarean section & $(34 / 41)$ & 82.93 \\
\hline
\end{tabular}

\section{DISCUSSION}

The queen cat is a sensitive and subtle animal, so all steps to treat dystocia need gentleness, confidence, and complete all physical examination before deciding the dystocia treatment method.

Data of the present study was in agreement with the previous report (Ekstrand and Forsberg, 1994) who refers that the maternal origin of dystocia in the cat was considered the major percent and the fewer causes related to fetal origin with no clear reason. The present study referred to the high incidence of uterine inertia as a major cause of the maternal origin of dystocia; these data were in agreement with another previous report in queen and different animals (Jutkowitz 2005; Sahoo et al., 2018).

Primary or secondary uterine inertia is the physiological process where the uterus fails to complete normal myometrial contraction waves due to muscle fatigue which coordinates the partition advances process (Jackson 2004). The other reason for uterine inertia is failing to respond to oxytocin action due to hormonal disturbance or pathophysiological conditions which prevent initiate response to hormonal changes at the onset of parturition, lack of calcium which play an important role in muscle contraction (Pretzer, 2008).

Medical treatment in the present study includes using estradiol hormone followed by oxytocin and $\mathrm{Ca}^{++} ;$Technically, the present study disagrees with previous reports (Pulfer and Riese, 1991; Pretzer 2008 ). These reports include using only oxytocin and $\mathrm{Ca}^{++}$for treatment of partial or closed cervix. The reason why using two hormones instead of one in cases of ring womb was related to the action of these agents which may be classified into two categories: action that directly affects the uterus and invented opening cervix or condition similar to estrus through the use of estrogen (Haimerl et $\boldsymbol{a l}$. , 2017) and also increased myometrial tone and movement, as well as activation of uterine immune systems (Quiñones-Jenab et al.,
1997). The other advantage of using estrogen was regulating and synthesizing oxytocin receptors in the uterus (Pooja and Shamas 2017). The potential force to evacuate fetus outside the uterus can be invented by injecting oxytocin hormone, which causes major uterine muscles. This activity is conjugated with the successful benefit work of estrogen (Ucmak, et al., 2017).

Data of the present study approved the result of previous reports who refers to use Caesarean section as the best way with a high percentage of success to treatment dystocia in queen what matter the causes of difficult birth originated (Dar et al., 2015; Olivira 2016; Talukder et al., 2021).

The definition of a successful Caesarean section includes all producers dealing with the operation, including anesthesia, fluid therapy, time from the beginning of clinical labor signs, animal body condition, and personal experience and post-operative care; all these factors determine success or reduce prognosis expectation Caesarean section (Trass, 2008). The complication with parturition in queen which may interfere with normal delivery reported in previous studies like ovariohysterectomy (Talukder et al., 2021), uterine prolapse (Ucmak et al., 2018), uterine torsion (Sahoo et al., 2018), and dystocia due to ectopic artery (Stedile et al., 2011).

These complications may eliminate free choices for treatment dystocia and retracted toward Csection or ovariohysterectomy choice. In conclusion, Caesarean section is considered the best method for treating dystocia in the cat if done in the right procedures. According to the author's experience, hormonal treatment should contain estradiol- oxytocin protocol with $\mathrm{Ca}^{++}$injection

\section{CONCLUSION}

Results of the present study conclude the best method for treating dystocia in cats was $\mathrm{C}$-section. The author advised using Estrogen and Oxytocin with $\mathrm{Ca}^{++}$ to treat non-obestracting dystocia instead of using oxytocin and $\mathrm{Ca}^{++}$alone.

\section{ACKNOWLEDGMENT}

The author is very thankful to the University of Mosul/ College of Veterinary Medicine for their offer facilities, which helped improve the quality of this work; we are also grateful to Dr. Ahmed Anmar and Dr. Thamer Ahmed Hasson for assistant and provide data from their owns clinic.

\section{Declaration of Conflicting Interests}

The authors revealed that there was no potential conflicts of interest. 


\section{REFERENCES}

BAROLIA, Y., PUROHIT, G.N., KUMAR, P., PRAJAPUT, L.N., and YADSV, S., 2010. Dystocia due to secondary uterine inertia in a bitch. J. canine develops. Res., 6:66-68. DOI: $10.13140 /$ RG.2.2.29601.45928

DAR, K.H., ANSARI, M.M., QADRI S.A., BABA, M.A., and KUMAR, M., 2015. Dystocia and its surgical management in Siamese queen. The blue cross book., 31: 40-41.

EKSTRAND, C., and FORSBERG, L., 1994. Dystocia in cat: a retrospective study of 155 cases. J. small animal practice., 35(9): 459-464.

https://doi.org/10.1111/j.1748-5827.1994.tb03951.x

GUNN-MOORE, D.A., and THRUSFIELD, M. V., 1995. Feline dystocia: Prevalence and association with cranial conformation and breed. Veterinary Record., 136:350 353. DOI: 10.1136/vr.136.14.350.

HAIMERAL, P., ARLT, S., BOECHARDT, S., and HEUWIESER, W., 2017. Antibiotic treatment of metritis in dairy cows - A meta-analysis. J. Dairy Sci., 100(5):3783-3795.https://doi.org/10.3168/jds.2016-11834

JAKSON, PG. 2004. Handbook of veterinary obstetrics. Elsevier Limited. $2^{\text {nd }}$ ed. PP: 141-166.

JUTKOWITZ, L.A. 2005. Reproductive emergencies. Vet Clin Small Amin Pract., 35:397-420. DOI: 10.1016/j.cvsm.2004.10.006

JYOTHI, S., and RAJESH, K., 2018. Cesarean section in canine: case report. The pharma innovation J., 7(4): 561-562.

LI, P., WANG, L, QIAN X., MORSE, A., GRAFILD, RE., and LIU, H., 2021. A study of uterine inertia on spontaneous of labor using uterine electromyography. Taiwanese j. Obstetrics and Gynecology., 60, 449-453. https://doi.org/10.1016/j.tjog.2021.03.010

OLIVERA, S., HAYASHI, R., DALANEZI, F., ARAUJO, E., ZAHAN, F., SILVA, L., RODRIGUES, J., and PRESTES, N., 2016. Uterine torsion with 1080 rotation in queen with closed-cervix pyometra. Acta Scientiae Veterinariae., 44 (supl 1):111. DOI: https://doi.org/10.22

OLIVIRA, K.S. 2016. Dystocia in dogs and cats: main causes. World Small Animal Association Congress Proceeding. Cartagena, CO: World Small Animal Veterinary Association(WSAVA).

POOJA, MS., and SHAMAS, M., 2017. Oxytocin- The Hormone of Love. Journal of Pharmacy and Biological Sciences., 12(6):1-9. DOI: 10.9790/3008-1206060109

PRETZER, S.D., 2008. Medical management of canine and feline dystocia. Theriogenology., 70: 332-336. DOI: 10.1016/j.theriogenology.2008.04.031.

PULFER, KW., and RIESE, R.L., 1991. Treatment of Postpartum Metritis in Dairy Cows. Iowa State University Veterinarian., 53(1), 27-31.

https://lib.dr.iastate.edu/iowastate_veterinarian/vol53/iss1/6

PUROHIT, G. Y., BAROLIA, Y., SHEKHAR, G., and KUMAR, P., 2011. Maternal dystocia in cows and buffaloes. A review. Open Journal of Animal Science., 41-53. DOI:10.4236/ojas.2011.12006.

QUINONES-JENAB， V., JENAB，S., OGAWA，S., ADAN, R.M., BURBACH, J.H., and PFAFF, D.W., 1997. Oxytocin Receptor Messenger
Ribonucleic Acid Expression in the Uterus, Pituitary, and Forebrain of the Female Rat. Neuroendocrinology., 65 (1):9-17.

SAHOO, A.H., NATH, H., NAHAK, A., BEHERA, S.S., PARIJA, D., and NAYAK, S.S., 2018. Surgical management of dystocia due to secondary uterine inertia in a dog-case report. EC Veterinary Science.,3 (1): $260-265$.

DOI: 10.46998/IJCMCR.2020.04.000087

STEDILE, R., OLIVIRA, S.T., MUCCILLO, M.D.S., CONTESINI, E.A., and Beck, C.A.D., 2011. Dystocia in cat due to an ectopic artery. Vet. Recorded., 169 (21):1-1. DOI: 10.1136/vr.d5516.

TALUKDER, A., DAS, Z., RAHMAN M.A., RAHMAN M.T., and RAHMAN A.N.M.A., 2021. Caesarean Section followed by ovariohystectomtomy in a Bangladeshi domestic cat: A surgical intervention for management of dystocia due to partial primary uterine inertia. Vet. Med. Sci., 00: 1-5. DOI: 10.1002/vms3.501.

TRASS, A.M. 2008. Surgical management of canine and feline dystocia. Theriogenology., 70 (3):337-342. DOI: 10.1016/j.theriogenology.2008.04.014.

UCMAK, Z.C., UCMAK, M., CETIN, A.C., and TEK, C., 2018. Uterine prolapse in pregnant cat. Turkish Journal of veterinary and animal science., 24:500-502. DOI: $\underline{10.3906 / \text { vet-1803-90. }}$

How to cite this article:

Uday, T. Naoman, 2021. Causes and Treatment of Feline Dystocia. Journal of Applied Veterinary Sciences, 6 (4): 28 - 31 .

DOI:https://dx.doi.org/10.21608/javs.2021.87891.1093 